Methods The study included 72 final year medical students in the academic year 2010-2011. The students were asked to freely evaluate their selves in the final theory, traditional long case and OSCE in pediatrics by putting a score representing their performance in these exams. The students self-rating was compared with the actual scores these students obtained.

Results There was a significant correlation between students selfrating and the actual students scores in the final exam in pediatrics.

Conclusion In the presence of a consensus among departments on the level of knowledge and skills that need to be mastered by students during undergraduate medical education, and the implementation of active training program; students self evaluation could be used as an additional method of students evaluation and assessment.

\section{CHARACTERIZATION OF KEY ENZYMES OF THE STEROID BIOSYNTHESIS IN PRETERM INFANTS}

doi:10.1136/archdischild-2012-302724.1021

1J de Laffolie, 'L Kästner, 1,2SA Wudy, 'B Kampschulte, 'B Grofer, ${ }^{3} \mathrm{RH}$ Bödecker, ${ }^{4} \mathrm{M}$ Heckmann. 'General Pediatrics and Neonatology; ${ }^{2}$ Steroid Laboratory; ${ }^{3}$ Institute of Medical Statistics, University of Gießen, Gießen; ${ }^{4}$ Department of Neonatology, University of Greifswald, Greifswald, Germany

Background A suspected cause for relative adrenal insufficiency in preterm infants is the immaturity of adrenal key enzymes for steroid synthesis (3ß-hydroxysteroiddehydrogenase (3ß-HSD), 11ß-hydroxylase (11ß-HYD)). The fetus lacks 3ß-HSD activity until the last trimenon (requiring placental progesterone) and active cortisol concentration is regulated by the final step of synthesis $11 B-$ HYD and inactivation by 11ß-hydroxysteroiddehydrogenase type 2 (11ß-HSD2). In this study we estimate enzyme activity in preterm infants and compare steroid profiles of preterm infants $<30$ weeks gestational age (GA) and above.

Method A 24 hour profile of glucocorticoid metabolites was obtained in the urine of 61 preterm infants of $<30$ wks GA and 81 preterm infants > 30 wks GA using gaschromatographymassspectrometry (GC-MS).

Results Patients $<30$ wks GA in contrast to the patients $>30$ wks displayed a significant increase in 3B-HSD activity from day 3 to week 3. 11ß-HYD activity decreased significantly until third week of life, this trend was stronger in preterm infants $<30$ weeks. In patients $<30$ weeks GA, 11ß-HSD activity decreased postnataly until the third week of life to the level of more mature patients.

Conclusion Preterm infants $<30$ weeks showed significant changes in enzyme activity, possibly a sign of maturation processes, that are not observed in patients $>30$ weeks GA.

There was no significant difference between ill and well preterm infants, potentially signifying insufficient cortisol response and validating further study in stress response at different stages of maturation.

\section{IMMUNOREGULATORY MECHANISMS OF CHILDS FOOD IN THE CHILDREN WITH DISPEPSIA SYNDROM}

doi:10.1136/archdischild-2012-302724.1022

OM Horlenko, UG Dubinina, BM Halay. Pediatrics with Infectious Diseases, Uzhgorod National University, Medical Faculty, Uzhgorod, Ukraine

Background We studied the influence of child's food on the state of homoeostasis in the children and developed recommendations by correction of dyspepsia syndrome.

Materials Were observed 27 children with dispepsia syndrom in early-aged children (2-6 months), who used nutritive correction by therapeutic baby's formula «Humana HN (Therapeutic Diet) + MCT (Medium Chain Triglycerides)».
Results The positive dynamics of use of child's food was confirmed of the clinical symptoms at duration of Dyspepsia syndrome, condition of peripheral blood, level of electrolyte exchange, hormonal tests, cytocines levels and production of endogenous If $-\gamma$. The level of IL-2 $(2.76 \pm 0.48$ to $3.36 \pm 0.53 \mathrm{mkmoll} / \mathrm{l})$ had tendency to the increase. That presents stimulation of proliferation and differentiation of activated T-cell to Thlimphocytes. Biological activity of IL-2 presence role of the typical TGF of cells of limphatic mieloid complex. The levels of IL- 4 also have a tendency to the decline in the reference dates $(16.48 \pm 1.78$ to $15.73 \pm 1.48 \mathrm{mkmoll} / \mathrm{l})$. IL-4 is known to increase the level of production of IgE, what is confirmed the decline of level of $\operatorname{IgE}$ in our researches. Level of IF- $\gamma$ has a tendency to the increase(38.9 \pm 1.74 to $40.1 \pm 1.24 \mathrm{mkmoll} / \mathrm{l}$ ) and level of IgA has same tendency too. What stipulated an increase of immunoregulatory mechanisms of child's organism.

Conclusion Used of child's food provides more active differentiation of cells of granulocytic and monocytic pool. An increase the level of IgA testifies to the improvement of local immunity by an obstacle fixing of bacteria and viruses on mucus shells. The values of IgE decreased, what represented hypoallergic influences of child's feeding.

\section{SALT CONSUMPTION, FRUIT AND VEGETABLE INTAKE AND LONG-TERM BLOOD PRESSURE DEVELOPMENT IN HEALTHY CHILDREN AND ADOLESCENTS}

doi:10.1136/archdischild-2012-302724.1023

L Shi, D Krupp, T Remer. DONALD Study, University of Bonn, Research Institute of Child Nutrition, Dortmund, Germany

Background Low salt consumption and high fruit \& vegetable intake (FVI) have been shown to reduce blood pressure (BP) in adults. To date, longitudinal data regarding the relative effect strength of FVI and salt intake (SI) on BP development during growth is not available. We aimed to characterize the long term concomitant influences of SI and FVI on the BP development during childhood and adolescence.

Methods 435 healthy children and adolescents (aged 4-18 years), who had at least 3 repeated measurements of BP, 24-h urine collections, and 3-d weighed dietary records, were examined. Systolic BP (SBP) and diastolic BP (DBP) were determined by mercury sphygmomanometer using auscultatory method. SI was estimated by measurement of $24 \mathrm{~h}$-sodium-excretion.

Results SI tended to be positively associated with SBP $(p<0.1)$ in the pubertal group (aged 11-18yrs). An increase of $1 \mathrm{~g} / \mathrm{d}$ of SI was related to an increase of $0.2 \mathrm{mmHg}$ SBP. SI was not associated with $\mathrm{DBP}$ or SBP in prepubertal children (aged 4-10yrs). FVI was negatively associated with SBP $(p<0.05)$ and DBP $(p<0.1$, trend) in 4-10 yr-olds. The increase of SBP by a $100 \mathrm{~g} / \mathrm{d}$ decrease in FVI was comparable with the increase of SBP by a $1 \mathrm{~g} / \mathrm{d}$ increase in SI. No FVI effect was observed in 11-18 yr-olds.

Conclusion Increased FVI may already be beneficial for BD development during childhood. Unfavorable changes of $\mathrm{BD}$ with higher SI were not yet observed during childhood; seem to develop however during adolescence.

Supported by BMELV [grant number 2811HS007].

\section{INFLUENCE OF BLOOD PRESSURE UPON REGULATION OF LIPID METABOLISM IN OBESE CHILDREN}

doi:10.1136/archdischild-2012-302724.1024

1P Sinitsyn, ${ }^{2 M}$ Shcherbakova, 'A Sherashov, ${ }^{3} \mathrm{E}$ Petriaykina. 'RNRMU; ${ }^{2}$ The Research Institute of Nutrition, RAMS; ${ }^{3}$ The Morozov Children's City Clinical Hospital, Moscow, Russia 
Background Disregulation of blood pressure (BP) and lipid metabolism is the basis of metabolic syndrome (MS), but interrelation of these MS components is not well studied today.

Aim To investigate influence of BP upon regulation of lipid metabolism in obese children.

Patients and Method 40 obese patients aged 10-16 years (13.9 \pm 0.27 y.o.) with high BP (HBP; $143.6 \pm 1.1 / 82.4 \pm 2.9 \mathrm{~mm})-1^{\text {st }}$ group. 40 obese patients with normal BP $(118.25 \pm 1.0 / 69 \pm 0.8 \mathrm{~mm}$, $\mathrm{p}<0.01)$ - comparison group ( $2^{\text {nd }}$ group). Examination included BP measurement and analysis of lipid profile.

Results Dyslipidemia in $1^{\text {st }}$ group was significantly more frequent than in $2^{\text {nd }}$ group: $85 \%$ versus $67.5 \%(p<0.05)$. Comparison of lipid spectrum showed that different disorders of lipid metabolism were more frequent and more significant in $1^{\text {st }}$ group in comparison with $2^{\text {nd }}$ : hypertriglyceridemia $-57.5 \%$ versus $22.5 \% \quad(p<0.01)$ and $2.36 \pm 0.15 \mathrm{mmol} / \mathrm{l}$ (mean value) versus $1.64 \pm 0.04 \mathrm{mmol} / \mathrm{l}(\mathrm{p}<0.01)$; decreased HDL-C $-37.5 \%$ versus $10 \%(p<0.01)$ and $0.91 \pm 0.01$ $\mathrm{mmol} / \mathrm{l}$ versus $1.03 \pm 0.02 \mathrm{mmol} / \mathrm{l}(\mathrm{p}<0.05)$; increased LDL-C $-45.0 \%$ versus $45.7 \%$ and $3.72 \pm 0.11 \mathrm{mmol} / 1$ versus $3.32 \pm 0.14 \mathrm{mmol} / \mathrm{l}$ $(p=0.06)$; increased index of atherogenicity $-75 \%$ versus $60 \%$ $(p<0.05)$ and $3.93 \pm 0.1$ versus $3.12 \pm 0.1(p<0.01)$.

Conclusion Arterial hypertension in obese children was associated with more frequent and significant disorders of lipid metabolism. So, arterial hypertension in obese children should be estimated as an additional risk factor of atherogenicity.

\section{THE ASSESSEMENT OF THE VITAMIN D SUPPLY IN POLISH CHILDREN AT THE AGE OF 9-12 YEARS - MULTICENTRE RESEARCH}

doi:10.1136/archdischild-2012-302724.1025

'D Chlebna-Sokol, ${ }^{2} \mathrm{~J}$ Golec, ${ }^{2} \mathrm{~J}$ Karalus, ${ }^{3} \mathrm{ZP}$ Halaba, ${ }^{4} \mathrm{E}$ Karczmarewicz, ${ }^{5} \mathrm{~J}$ Konstantynowicz, ${ }^{6} \mathrm{~B}$ Kulik-Rechberger, ${ }^{7} \mathrm{M}$ Niedziela, ${ }^{4} \mathrm{~A}$ Dobrzańska. ${ }^{1}$ Propedeutic Paediatrics and Bone Metabolic Diseases; ${ }^{2}$ Medical University of Lodz, Lodz; ${ }^{3}$ Medical University of Silesia, Katowice; 'The Children's Memorial Health Institute in Warsow, Warsow; ${ }^{5}$ University of Bialystok, Bialystok; ${ }^{6}$ University of Lublin, Lublin; 'University of Poznan, Poznan, Poland

Introduction It is universally known that the systemic deficiency of vitamin $\mathrm{D}$ may hamper the correct peak bone mass acquistion.

Aim The aim of the study was to determine the vitamin D supply in schoolchildren in Poland.

Patients and methods The study comprised 6 research centers from Poland. The healthy schoolchildren at the age of 9-11.99 were examined. In every child the liver metabolite of vitamin D was detected twice: after the winter and summer. The serum was analysed with the immunochemiluminescence method. The sufficient $25 \mathrm{OHD}$ serum concentration was recognized at range of 20-100 ng/ml

Results The 715 of children were examined. The greatest vitamin D shortages were observed in Szczecin and Białystok - in 95\% and in $90 \%$ children. In Katowice and Lublin the lower concentration was detected in 89\% and 88\% of children and in Łódź and Poznań in $77 \%$ and $74 \%$. The results of the $250 \mathrm{HD}$ improved considerably after the summer. The greatest shortages were obtained in Poznań and Szczecin - in 52.9\% and 42.1\%. In Łódź the decreased concentration was observed in $41.5 \%$ of children. The lowest shortages were revealed in Lublin, Białystok and Katowice- in 28\%, 26.3\% and $26.3 \%$.

\section{Conclusions}

1. The lower concentration of vitamin $\mathrm{D}$ in as many children indicates on adverse diet and climatic conditions.

2. The results of this study confirm the neccesity of the prophylaxis of vitamin D deficiency in schoolchildren in Poland

3. The considerable improvement of the $25 \mathrm{OHD}$ serum concentration after the summer may provide favourable influence of the sunlight.

\section{EXCESSIVE FLUORIDE INTAKE IS ASSOCIATED WITH HYPERPARATHYROIDISM AND HYPOTHYROIDISM IN CHILDREN AND ADOLESCENT, JEDDAH- SAUDI ARABIA}

doi:10.1136/archdischild-2012-302724.1026

${ }^{1} \mathrm{RM}$ Al-Raddadi, ${ }^{2} \mathrm{SM}$ Bahijri, ${ }^{2} \mathrm{~T}$ Al-Khateeb. ${ }^{1}$ Postgraduate Center for Family and Community Medicine; ${ }^{2}$ King Abdulaziz University, Jeddah, Saudi Arabia

Background Exposure to Fluoride $(F)$ has increased significantly, so that individuals may be consuming more than recommended. Reported effects of excessive intake include reduced serum free thryroxine (FT4), triiodothyronine (FT3), calcium and increased parathyroid hormone (PTH) concentration.

Objective To investigate the prevalence of excessive Fluoride intake in apparently healthy children and adolescents, and explore its association changes in thyroid and parathyroid function in Jeddah-Saudi Arabia.

Methods 145 apparently healthy children and adolescents were recruited. 60 individuals satisfied selection criteria, and agreed to be enrolled. Subjects were examined dentally and clinically. Weights and heights were measured to calculate body mass index. Dental hygiene practices and fluoride intakes were recorded using recall method and food frequency questionnaires. Blood samples were obtained for the estimation of free thyroxine, triiodothyronine, thyroid stimulating hormone, Parathyroid hormone, calcium and phosphate. Fluoride was estimated in a samples of drinking water, beverages, and fasting urine of subjects. Total Fluoride intakes were calculated and used to subdivide groups into high and low or optimal intake subgroups.

Results Excessive Fluoride intake was identified among $36.7 \%$ of the individuals.

Calculated intake correlated with urinary excretion $(\mathrm{r}=0.54$, $\mathrm{p}=0.0003$ ).

Significantly higher mean thyroid stimulating hormone and Parathyroid hormone and lower mean of free thyroxine, triiodothyronine, calcium and phosphate were found in various high intake subgroups, with some subjects having abnormal values.

Conclusion Excessive F intake is common, and is associated with hyperparathyroidism and hypothyroidism in studied population.

\section{MINERAL PROFILE OF PNEUMOCOCCAL DISEASES IN THE CHILDREN}

doi:10.1136/archdischild-2012-302724.1027

${ }^{1} \mathrm{OM}$ Horlenko, ${ }^{2} \mathrm{VI}$ Rusyn, ${ }^{2} \mathrm{OO}$ Boldizhar, ${ }^{2} \mathrm{FV}$ Horlenko, ${ }^{2} \mathrm{NY}$ Kishko, ${ }^{1} \mathrm{AO}$ Yankovska, ${ }^{3} \mathrm{OM}$ Moskal, 'OA Pushkarenko, 'Al Tomey, 'GB Kosssey. 'Pediatrics and Infectious Diseases; ${ }^{2}$ Surgical Diseases; ${ }^{3}$ Internal Medicine, Uzhgorod National University, Medical Faculty, Uzhgorod, Ukraine

Background and Aims A mineral homeostases is assotiation of processes of sorbtion, distributing, and elimination of mineral composition. Mineral matters play an important role in maintenance of acid-basic balance, osmolality, participate in the function of many enzymic systems, assists development of inflammatory process.

Methods Focus group included 21 children, aged $11.1 \pm 0.95$ with community-acquired pneumonia, Pneumonia lower lobes acuta (PLA) in which was identificate S.Pneumonia.

Result In the majority of cases the results of physical examination were satisfactory. The level of zinc in blood plasma of PA patients were $0.68 \pm 0.17 \mathrm{mkg} / 1,0,670.03 \mathrm{mkg} / \mathrm{l}$ in urine, copper $-0.42 \pm 0.03$ $\mathrm{mkg} / \mathrm{l}$ in blood plasma, $0.36 \pm 0.02 \mathrm{mkg} / \mathrm{l}$ in urine, iron- $0.75 \pm 4.2$ $\mathrm{mkg} / \mathrm{l}$ in blood plasma, $23.48 \pm 1.75 \mathrm{mkg} / \mathrm{l}$ in urine, phosphorus $473.10+11.25 \mathrm{mkg} / \mathrm{l}$ in blood plasma, $312.50+11.84 \mathrm{mkg} / \mathrm{l}$ in urine, iodine $-70.23 \pm 5.81 \mathrm{mkg} / \mathrm{l}$ in blood plasma, $60.19 \pm 1.21 \mathrm{mkg} / \mathrm{l}$ in urine. There were a positive correlation with the levels of $\mathrm{Fe} / \mathrm{Cu}$ of blood serum $(r=0.64)$. With the level of calcium ratio of $\mathrm{Fe} / \mathrm{Cu}$ had a 